\title{
Extra legem, intra ius: Allgemeine Rechtsgrundsätze im Europäischen Privatrecht
}

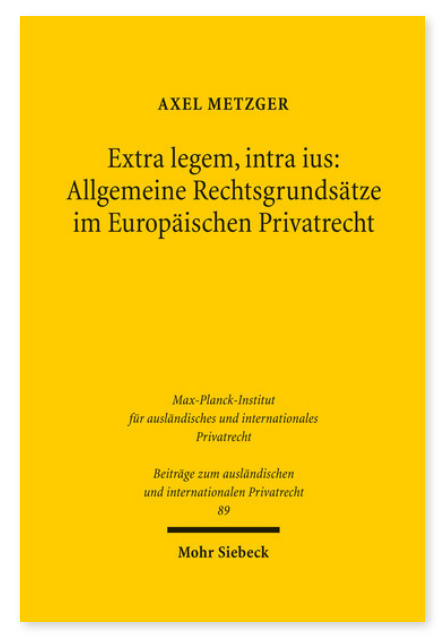

2009. XXVI, 622 Seiten. BtrIPR 89

ISBN 978-3-16-151082-3

DOI 10.1628/978-3-16-151082-3

eBook PDF 119,00 €

ISBN 978-3-16-149795-7

Leinen $119,00 €$
Der allgemeine Rechtsgrundsatz (general principle, principe général) ist als Normtypus von hervorgehobener Bedeutung für das europäische Privatrecht. Zum einen greift der Europäische Gerichtshof seit den 1950er Jahren regelmäßig auf allgemeine Rechtsgrundsätze (oder »Prinzipien«) zurück, um das nach wie vor lückenhafte Gemeinschaftsrecht zu ergänzen und auszulegen. Zum anderen arbeiten mehrere Wissenschaftsprojekte an der Sammlung rechtsvergleichend ermittelter »Principles ». Die EuGH-Rechtsprechung und die Arbeit der Wissenschaftlergruppen stellen dabei nur einen Ausschnitt des Gesamtphänomens dar. Rechtsgrundsätze erfüllen auch innerhalb der nationalen Systeme und im Einheitsrecht zentrale Funktionen bei der Rechtsfindung. Axel Metzger entwickelt im Grundlagenteil des vorliegenden Buches eine einheitliche Terminologie und Typologie der allgemeinen Rechtsgrundsätze und beleuchtet die erkenntnistheoretischen Grundlagen. Es zeigt sich, dass Prinzipien auf einem Schluss von besonderen Rechtsregeln auf einen »allgemeinen« Grundsatz basieren. Die Anforderungen an induktive Schlussverfahren können deswegen für die Untersuchung fruchtbar gemacht. Den Schwerpunkt der Untersuchung bildet die Behandlung der verschiedenen Ebenen des europäischen Privatrechts (Recht der

Mitgliedstaaten, Gemeinschaftsrecht, Einheitsrecht, lex mercatoria ), für welche der Autor jeweils die praktische Bedeutung von Rechtsgrundsätzen, die Methode ihrer Herleitung, die Funktionen sowie die Frage der rechtlichen Geltung analysiert. Zum Vergleich zieht er das Recht der Vereinigten Staaten heran.

Axel Metzger ist Professor für Bürgerliches Recht und Immaterialgüterrecht, insbesondere Gewerblicher Rechtsschutz an der Juristischen Fakultät der Humboldt-Universität zu Berlin.
Jetzt bestellen:

https://mohrsiebeck.com/buch/extra-legem-intra-ius-allgemeine-rechtsgrundsaetze-im-europaeischen-privatrecht-

9783161510823?no_cache $=1$

order@mohrsiebeck.com

Telefon: +49 (0)7071-923-17

Telefax: $+49(0) 7071-51104$ 